\title{
Lung function and clinical risk factors for asthma in infants and young children with recurrent wheeze
}

\author{
L M Borrego, ${ }^{1}$ J Stocks, ${ }^{2}$ P Leiria-Pinto, ${ }^{1}$ I Peralta, ${ }^{1}$ A M Romeira, ${ }^{1}$ N Neuparth, \\ J E Rosado-Pinto, ${ }^{1}$ A-F Hoo ${ }^{2}$
}

- Additional material published online only at http://thorax.bmj. com/content/vol64/issue3

${ }^{1}$ Serviço de Imunoalergologia, Centro Hospitalar Lisboa CentralHospital de Dona Estefania, Lisboa, Portugal; ${ }^{2}$ Portex Respiratory Unit, UCL Institute of Child Health and Great Ormond Street Hospital NHS Trust, London, UK

Correspondence to: Dr L M Borrego, Serviço de Imunoalergologia, Centro Hospitalar Lisboa CentralHospital de Dona Estefania, Rua Jacinta Marto, 1169-045 Lisboa, Portugal; miguel.borrego@ sapo.pt

Received 31 March 2008 Accepted 30 September 2008

Published Online First

13 November 2008

\section{ABSTRACT}

Background: Although several risk factors for asthma have been identified in infants and young children with recurrent wheeze, the relevance of assessing lung function in this group remains unclear. Whether lung function is reduced during the first 2 years in recurrently wheezy children, with and without clinical risk factors for developing subsequent asthma (ie, parental asthma, personal history of allergic rhinitis, wheezing without colds and/or eosinophil level $>4 \%$ ) compared with healthy controls was assessed in this study.

Methods: Forced expiratory flows and volumes in steroid naïve young children with $\geqslant 3$ episodes of physician confirmed wheeze and healthy controls, aged 820 months, were measured using the tidal and raised volume rapid thoracoabdominal compression manoeuvres. Results: Technically acceptable results were obtained in 50 wheezy children and 30 controls using tidal rapid thoracoabdominal compression, and 44 wheezy children and 29 controls with the raised volume technique. After adjustment for sex, age, body length at test and maternal smoking, significant reductions in z scores for forced expiratory volume at $0.5 \mathrm{~s}$ (mean difference (95\% CI) $-1.0(-1.5$ to -0.5$))$, forced expired flow after $75 \%$ forced vital capacity (FVC) has been exhaled $\left(\mathrm{FEF}_{25}\right)$ $(-0.6(-1.0$ to -0.2$))$ and average forced expired flow over the mid $50 \%$ of FVC $\left(\mathrm{FEF}_{25-75}\right)(-0.8(-1.2$ to $-0.4)$ ) were observed in those with recurrent wheeze compared with controls. Wheezy children with risk factors for asthma $(n=15)$ had significantly lower $z$ scores for FVC $(-0.7(-1.4$ to -0.04$))$ and $\mathrm{FEF}_{25-75}(-0.6(-1.2$ to -0.1$)$ ) than those without such risk factors $(n=29)$. Conclusions: Compared with healthy controls, airway function is reduced in young children with recurrent wheeze, particularly those at risk for subsequent asthma. These findings provide further evidence for associations between clinical risk factors and impaired respiratory function in early life.

Recurrent wheeze is a common symptom during infancy and early childhood. ${ }^{12}$ Although the majority of children will outgrow their symptoms, some go on to develop asthma. ${ }^{3}{ }^{4}$ Early onset of asthma has been associated with persistence of symptoms and reduced lung function that continues into adulthood. ${ }^{5-7} \mathrm{~A}$ recently described clinical index considers young children with recurrent wheezing in the first 3 years of life to be at high risk of developing asthma if there is a parental history of asthma or personal history of eczema, or if two of the following are present: personal history of allergic rhinitis, wheezing without a cold and/or serum eosinophil level $>4 \%{ }^{8}$ Other predictive indices additionally take immunological measurements ${ }^{1}$ and clinical parameters into account ${ }^{9}$ but these indices cannot be easily applied to daily practice.

Apart from clinical risk factors, lung function evaluation may contribute to the assessment of wheezing phenotypes during early life. A reduction in premorbid lung function has been associated with increased risk of wheezing in the first years. ${ }^{310-12}$ Tracking of lung function (whereby those with lower lung function initially continue to do so thereafter) has been well documented during infancy, ${ }^{13} 14$ childhood $^{1516}$ and adulthood. ${ }^{517}$ However, the association between wheezing phenotypes and early airway function remains unclear. The Tucson study reported a link between reduced maximal forced expiratory flow at functional residual capacity $\left(\mathrm{V}^{\prime}{ }_{\text {maxFRC }}\right)$ from the tidal rapid thoracoabdominal compression (RTC) technique, in the first weeks of life prior to the onset of respiratory symptoms, and transient wheeze but not with persistent wheeze. ${ }^{2}$ Similarly, data from Wilson et al found no association between wheezing beyond 4 years and reduced $V^{\prime}$ maxFRC at 4 weeks of age. ${ }^{18}$ In contrast, the Perth group reported that persistent wheeze/asthma at 11 years was associated with reduced premorbid $\mathrm{V}^{\prime}{ }_{\operatorname{maxFRC}}$ at 1 month. ${ }^{16} \mathrm{~A}$ further study observed that children with transient wheeze had lower $V^{\prime}$ maxFRC at 17 months compared with those with persistent wheeze. ${ }^{19}$ Others have suggested that asymptomatic children with evidence of flow limitation during tidal breathing in the first days of life are likely to have a higher risk of subsequent asthma. ${ }^{20}$

In recent years, several investigators have reported that, compared with tidal RTC manoeuvres, the raised volume RTC technique is more sensitive in distinguishing lung function between infants with and without respiratory disease. ${ }^{21-24}$ The raised volume technique has been used in children with ${ }^{24} 25$ and without recurrent wheezing ${ }^{26}$ but not, to our knowledge, to compare lung function in wheezy young children according to the risk of developing asthma.

This aim of this study was to assess whether lung function was reduced during the first 2 years of life in recurrently wheezy children with a high risk of developing subsequent asthma ${ }^{8}$ compared with age matched "low risk" wheezy children and healthy controls.

\section{METHODS \\ Subjects}

Infants and young children, aged between 8-20 months, with recurrent wheeze ( $\geqslant 3$ episodes of 
Figure 1 Flow diagram of recruitment process for lung function measurements in the wheezy children. LFT, lung function tests; RTC, rapid thoracoabdominal compression.

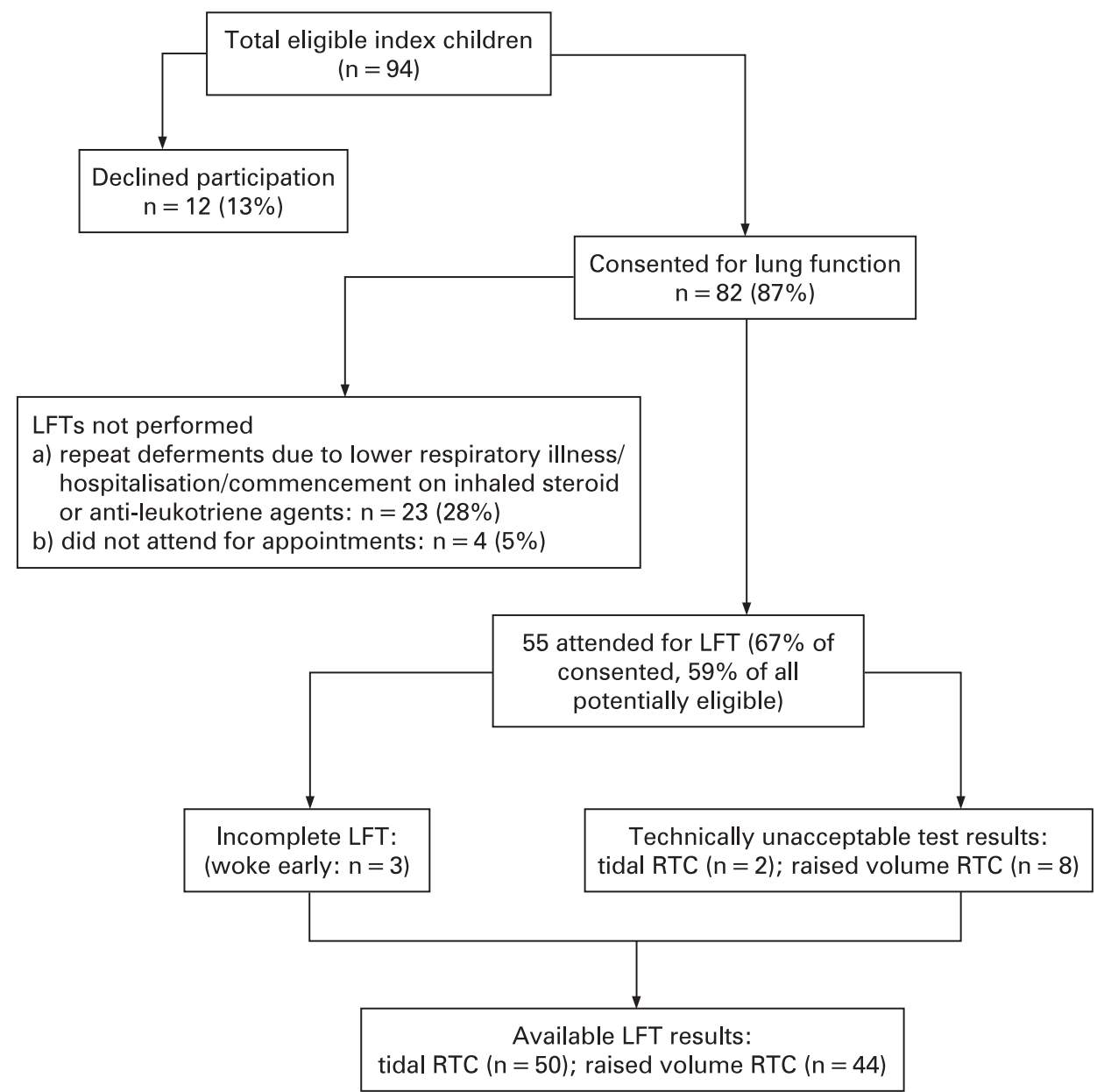

medically diagnosed wheeze) but prior to receiving any inhaled corticosteroid or anti-leukotriene agents, were recruited from the outpatient clinic in Hospital Dona Estefania, Lisbon (September 2005 to September 2007). Children requiring hospitalisation for exacerbations were ineligible for the study. Children were stratified into high and low risk for developing asthma. ${ }^{8}$

Age matched healthy children without a prior history of lower respiratory illness, wheeze or allergic disorders (food allergy, eczema) or parental asthma were recruited from those attending routine developmental screening appointments. Control children meeting the inclusion criteria, and who had been recruited to epidemiological studies at the UCL Institute of Child Health, London, UK, ${ }^{14}$ were also included in the study population.

All children were born $\geqslant 37$ gestational weeks with birth weight $>10$ th percentile, and any with cardiac, metabolic, neurological or gastrointestinal diseases, or upper airway pathology were excluded.

The ethics committees at the Lisbon and London institutions approved the study. Parents of participating children gave informed written consent and were present during measurements.

\section{Respiratory function tests}

At the time of the assessments, infants were free of respiratory symptoms or illness for at least 3 weeks. Weight and crownheel length were measured using digital scales and a calibrated stadiometer, and values expressed as $z$ scores. ${ }^{27}$ Lung function measurements were undertaken in the supine position during quiet sleep following oral administration of chloral hydrate (60$75 \mathrm{mg} / \mathrm{kg}$ ). Prior to sedation, the child's heart rate and oxygen saturation level were recorded, and continuous monitoring maintained throughout the test period.

Identical equipment (VIASYS Healthcare Masterscreen BabyBody, V.4.6, Hochberg, Germany) and standardised techniques, which adhered to international guidelines, ${ }^{28}{ }^{29}$ were used in both laboratories. The London team provided training for the Lisbon group and ongoing supervision throughout the study through inter-laboratory visits; all datasets were cross analysed anonymously. A lung inflation pressure of $30 \mathrm{~cm} \mathrm{H} \mathrm{H}_{2} \mathrm{O}$ was used during the raised volume test. ${ }^{28}$ At least two technically satisfactory and reproducible (within 10\%) partial and raised volume forced expiratory flow volume curves were collected. ${ }^{28} 29$ Detailed descriptions of both techniques, including quality control criteria, are available in the online supplement. Results were reported as $z$ scores, ${ }^{30}{ }^{31}$ values being considered abnormal if below $-1.96 \mathrm{z}$ score.

A questionnaire was completed by parents documenting smoking habits, family history of allergic illness and their child's respiratory symptoms or illnesses since birth. Peripheral blood samples for eosinophil levels were obtained in those with recurrent wheeze when seen at the outpatient clinics. ${ }^{8}$

\section{Sample size and statistical analysis}

Power calculations indicated that 35 children per group would provide $80 \%$ certainty of detecting differences of 0.67 in z scores 
Table 1 Comparison of wheezy and healthy children: background characteristics and lung function results

\begin{tabular}{|c|c|c|c|c|c|c|}
\hline Background details & $\begin{array}{l}\text { High risk } \dagger \\
\text { wheezy } \\
\text { children } \\
(\mathrm{n}=17)\end{array}$ & $\begin{array}{l}\text { Low risk } \dagger \\
\text { wheezy } \\
\text { children } \\
(\mathrm{n}=33)\end{array}$ & $\begin{array}{l}\text { All wheezy } \\
\text { children }(n=50)\end{array}$ & $\begin{array}{l}\text { Healthy controls } \\
(n=30)\end{array}$ & $\begin{array}{l}\text { Mean difference } \\
(95 \% \text { CI) All } \\
\text { wheezy - healthy } \\
\text { children }\end{array}$ & p Value \\
\hline Birth weight $(\mathrm{kg})$ & $3.4(0.5)$ & $3.3(0.4)$ & $3.3(0.4)$ & $3.3(0.4)$ & $0.02(-0.2$ to 0.2$)$ & 0.8 \\
\hline Birth weight $z$ score & $0.3(0.9)$ & $0.1(0.8)$ & $0.1(0.9)$ & $-0.2(0.8)$ & $0.3(-0.1$ to 0.7$)$ & 0.1 \\
\hline Male (n (\%)) & $9(53)$ & $23(70)$ & $32(64)$ & $18(60)$ & $4(-17$ to 25$)$ & $0.7 \S$ \\
\hline Postnatal age (weeks) & $60.6(16.9)$ & $64.6(16.6)$ & $63.2(16.6)$ & $55.0(17.0)$ & $8.1(0.4$ to 15.9$)$ & 0.04 \\
\hline Weight $(\mathrm{kg})$ & $11.2(2.2)$ & $11.0(1.6)$ & $11.1(1.8)$ & $9.7(1.2)$ & $1.4(0.7$ to 2.2$)$ & 0.0001 \\
\hline Weight z score & $0.7(1.6)$ & $0.3(1.1)$ & $0.4(1.3)$ & $-0.3(1.0)$ & $0.7(0.2$ to 1.3$)$ & 0.01 \\
\hline Length (cm) & $79.8(5.6)$ & $79.9(5.4)$ & $79.8(5.4)$ & $76.7(4.6)$ & $3.2(0.8$ to 5.5$)$ & 0.01 \\
\hline Length z score & $1.0(1.4)$ & $0.6(1.2)$ & $0.7(1.2)$ & $0.5(1.2)$ & $0.2(-0.3$ to 0.8$)$ & 0.4 \\
\hline \multicolumn{7}{|l|}{ Lung function indices } \\
\hline $\mathrm{V}_{\text {maxFRC }}^{\prime} \mathrm{z}$ score & $-2.2(1.0)$ & $-1.7(1.0)$ & $-1.9(1.0)$ & $-1.5(0.9)$ & $-0.4(-0.9$ to 0.1$)$ & 0.1 \\
\hline Respiratory rate (bpm) & $30.4(8.3)$ & $29.7(6.0)$ & $29.9(6.8)$ & $30.2(5.6)$ & $-0.3(-3.2$ to 2.7$)$ & 0.9 \\
\hline $\mathrm{Vt} / \mathrm{kg}(\mathrm{ml})$ & $10.0(1.5)$ & $9.8(1.1)$ & $9.9(1.2)$ & $9.9(1.5)$ & $-0.1(-0.7$ to 0.6$)$ & 0.9 \\
\hline$t_{\text {PTEF }} / t_{\mathrm{E}}$ & $0.24(0.1)$ & $0.26(0.1)$ & $0.25(0.1)$ & $0.29(0.1)$ & $-0.03(-0.1$ to 0.01$)$ & 0.2 \\
\hline
\end{tabular}

Data shown as mean (SD) for continuous and $\mathrm{n}(\%)$ for categorical variables.

§statistical significance was calculated using $\chi 2$ test.

${ }^{*} \mathrm{n}=15 ;{ }^{* *} \mathrm{n}=29 ;{ }^{* * *} \mathrm{n}=44 ;{ }^{* * *} \mathrm{n}=29$.

$\dagger$ †High risk" denotes wheezy children with parental history of asthma, or wheezing without colds and serum eosinophilia above $4 \%$; "Low risk" denotes wheezy children without such clinical features.

$\mathrm{FEV}_{0.5}$, forced expiratory volume at $0.5 \mathrm{~s}$; $\mathrm{FEF}_{75}$, forced expired flow after $75 \% \mathrm{FVC}$ has been exhaled; $\mathrm{FEF}_{25-75}$, average forced expired flow over the mid $50 \%$ of $\mathrm{FVC}$; $\mathrm{FVC}$, forced vital capacity; $\mathrm{t}_{\mathrm{TTEF}} / \mathrm{t}_{\mathrm{E}}$, ratio of time taken to reach peak tidal expiratory flow to total expiratory time; $\mathrm{V}_{\text {max }}{ }_{\text {mC, }}$ maximal forced flows at functional residual capacity; $\mathrm{Vt}$, tidal volume.

at the $5 \%$ significance level for the selected outcome variables between wheezy infants and controls. For subgroup analysis according to wheezing phenotype, 20 per group would provide $80 \%$ power to detect differences of 0.9 in $z$ score. ${ }^{32}$

Comparisons of group characteristics and lung function between study groups were performed using independent sample $t$ tests with $95 \%$ confidence intervals (CI) and $\chi^{2}$ tests. The extent to which recurrent wheeze is associated with lung function was also examined using multiple linear regression (MLR) (SPSS for Windows, V.15, Chicago, Illinois, USA) after adjustment for sex, age, body weight and length, and effects of potential confounding factors, such as maternal smoking.

\section{RESULTS}

Parents of 82/94 (87\%) eligible Lisbon wheezy children gave consent for lung function measurements and of these, 55/82 $(67 \%)$ attended for tests (fig 1). Technically satisfactory $\mathrm{V}^{\prime}$ maxFRC flow-volume curves were obtained in 50 wheezy infants whereas 44 had acceptable raised volume forced expiratory flow volume curves. In contrast, among the eligible Lisbon healthy children, 21/59 (36\%) families gave consent and of these, 14 (24\%) attended for tests. Technically acceptable data were obtained in 12 healthy Lisbon children for $V^{\prime}$ maxFRC and 11 for the raised volume technique. Technically satisfactory data using both partial and raised volume manoeuvres were collected in 18 healthy children in London.

At birth, there was no significant difference in gestational age, weight or prevalence of smoking during pregnancy between the Lisbon and London controls, nor were there any significant differences in age or body size at the time of the tests or lung function results (see table $\mathrm{E} 1$ in the online supplement).
Consequently, datasets from the two healthy subgroups were combined for comparison with wheezy children.

\section{Comparison of wheezy and healthy groups}

Gestational age of the wheezy group was 0.6 weeks lower than that of controls $(p<0.02)$ but there were no significant differences in sex, birth weight or maternal smoking during pregnancy (table 1). At the time of the tests, wheezy children were somewhat older, heavier and longer than the healthy controls, primarily because of deferment of testing following upper respiratory infections in the wheezy infants. After expressing weight and length as z scores to adjust for age and sex, the wheezy group remained significantly heavier than controls, with no difference in length (table 1). There was a non-significant tendency for weight gain since birth to be greater among wheezy children (mean (95\% CI) change in weight $z$ score 0.4 ( -0.1 to 1.0$)$ ).

Z scores for forced vital capacity (FVC), forced expiratory volume at $0.5 \mathrm{~s}\left(\mathrm{FEV}_{0.5}\right)$, forced expired flow after 75\% FVC has been exhaled $\left(\mathrm{FEF}_{75}\right)$ and average forced expired flow over the mid $50 \%$ of FVC $\left(\mathrm{FEF}_{25-75}\right)$ were all significantly lower in wheezy than in healthy children (fig 2) but no differences were observed in $V^{\prime}{ }_{\operatorname{maxFRC}} \mathrm{z}$ score, respiratory rate, tidal volume or ratio of time taken to reach peak tidal expiratory flow to total expiratory time ( $t_{\mathrm{PTEF}}: \mathrm{t}_{\mathrm{E}}$ ) between the groups (table 1 ).

Associations between lung function and wheezing phenotype were also examined after adjusting for factors that influenced lung function on univariable analysis (sex, birth weight $z$ score, age and test length and smoking during pregnancy). After adjustment for these covariants, significant reductions (mean (95\% CI), wheeze controls) were observed for FVC ( -42 ( -78 

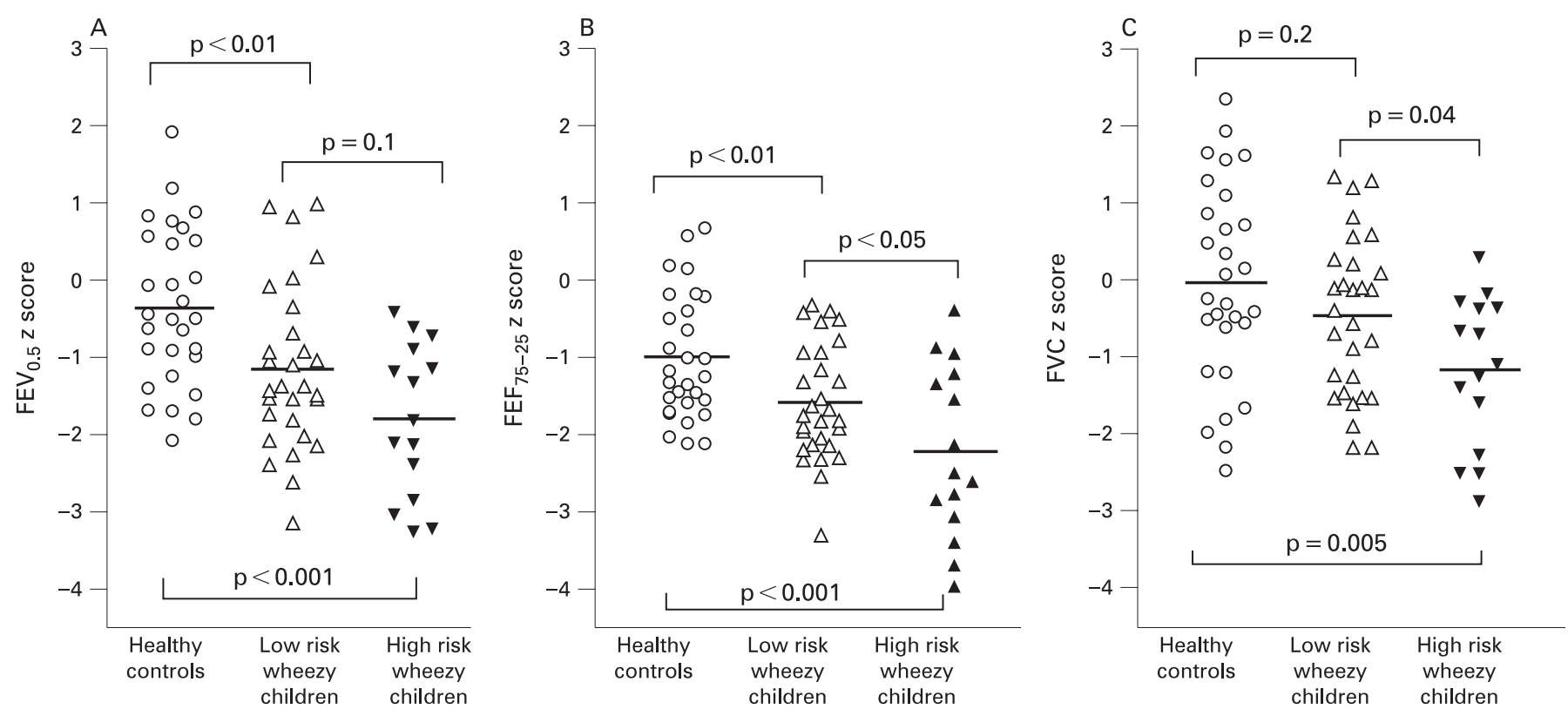

Figure 2 Comparison of $\mathrm{FEV}_{0.5}, \mathrm{FEF}_{75-25}$ and $\mathrm{FVC} z$ scores in healthy controls and wheezy subgroups. Results from individual children are shown, with mean values (indicated by the horizontal bar) for each subgroup. For mean difference and $95 \% \mathrm{Cl}$ of the difference between the subgroups, please refer to table 2. $\mathrm{FEV}_{0.5}$, forced expiratory volume at $0.5 \mathrm{~s}$; $\mathrm{FEF}_{25-75}$, average forced expired flow over the mid $50 \%$ of FVC; FVC, forced vital capacity.

to -6$) \mathrm{ml}$ ), $\mathrm{FEV}_{0.5}(-30$ ( -54 to -6$\left.) \mathrm{ml}\right), \mathrm{FEF}_{75}(-42$ ( -75 to $-10)$ ) and $\mathrm{FEF}_{25-75}(-70$ ( -117 to -23$\left.) \mathrm{ml} / \mathrm{s}\right)$. Addition of change in weight $z$ score since birth had minimal effect on these relationships.

After adjustment for other factors, FVC was 57 (21 to 92) ml higher in boys than girls and 26 (5 to 48) $\mathrm{ml}$ higher per unit increment in birth weight $z$ score. Maternal smoking was not significantly associated with any outcome on MLR. There was no association between $V^{\prime}{ }_{\max F R C}$ and wheeze on MLR analysis.

\section{Wheezing subgroups}

Among the 17 infants at high risk for subsequent asthma ${ }^{8}$ (table 1), 13 (76\%) had a history of parental asthma, five (29\%) a personal history of rhinitis, $12(71 \%)$ had wheezed without colds and nine (53\%) had serum eosinophil levels $>4 \%$. When dichotomised into wheezy subgroups according to these risk factors, there were no significant differences in background characteristics between the three groups, apart from controls being slightly more mature at birth (table 1). After adjusting for age and sex, both wheezing subgroups were significantly heavier than controls at the time of the test (mean (95\% CI) difference in weight $\mathrm{z}$ score for low risk wheezers (controls 0.6 (0.04 to 1.1) and high risk wheezers (controls 1.0 (0.3 to 1.8)).

$\mathrm{FEV}_{0.5}, \mathrm{FEF}_{75}$ and $\mathrm{FEF}_{25-75} \mathrm{z}$ scores were all significantly lower in both wheezing subgroups compared with healthy controls; FVC $\mathrm{z}$ score was also lower in the high but not the low risk group (table 2, fig 2). Compared with low risk wheezers, FVC and $\mathrm{FEF}_{25-75}$ were significantly reduced in high risk young children (table 2, fig 2). A significant difference in $\mathrm{V}^{\prime}$ maxFRC $z$ score was only observed between the high risk wheezers and healthy controls. No significant differences were seen in respiratory rate, tidal volume or $t_{\mathrm{PTEF}}: \mathrm{t}_{\mathrm{E}}$ between the three groups (table 2).

The associations between lung function and wheezing phenotype were also examined using MLR after adjusting for factors found to be significant on univariable analysis (sex, birth weight $\mathrm{z}$ score, age and length at test, and maternal smoking).
After adjustment for these covariants, FVC was significantly reduced in the high versus low risk group by -45 ( -89 to -2) $\mathrm{ml}$ whereas, despite a trend towards lower values among high risk children, there were no significant differences in $\mathrm{FEV}_{0.5}$ ( $-25(95 \%$ CI -56 to 7$)) \mathrm{ml}$ or $\mathrm{FEF}_{25-75}(-47$ ( -115 to 20$\left.) \mathrm{ml} / \mathrm{s}\right)$. Among the wheezy children, $\mathrm{FEF}_{25-75}$ was significantly lower $(-78(-149$ to -8$) \mathrm{ml} / \mathrm{s})$ in those whose mothers had smoked during pregnancy.

\section{DISCUSSION}

Findings from our study demonstrated that, after adjustment for sex, age, length and maternal smoking, forced flows and volumes from the raised volume technique, but not $\mathrm{V}_{\text {' maxFRC }}$ or any of the tidal breathing variables, were significantly reduced during the first 2 years of life in young children with recurrent physician confirmed wheeze compared with prospective healthy controls. Among recurrently wheezy infants, those with a positive clinical index for asthma had significantly reduced FVC and $\mathrm{FEF}_{25-75}$ than those without such risk factors.

\section{Strengths and limitations}

Interpretation of these findings and their clinical relevance depends on factors such as accuracy of measurements, lack of bias and the extent to which results can be generalised, as discussed below.

\section{Population}

Our sample included 59\% of eligible wheezy young children who presented at clinic during a 2 year recruitment period. In an attempt to study a relatively homogenous group and collect essential baseline data prior to long term interventions, young children with recurrent wheeze were only eligible if they had not yet received inhaled corticosteroids or anti-leukotriene therapy, or had been hospitalised during exacerbations. Similarly, since our research questions specifically related to risk factors for wheezing, healthy controls were only eligible if there was no prior history of lower respiratory illness, wheeze, 
Table 2 Mean difference $(95 \% \mathrm{CI})$ in lung function variables: wheezy subgroups versus healthy controls

\begin{tabular}{|c|c|c|c|}
\hline \multirow[b]{2}{*}{ Lung function indices } & \multicolumn{3}{|c|}{ Mean difference (95\% Cl) between subgroups } \\
\hline & $\begin{array}{l}\text { High risk wheezy - healthy } \\
\text { children }(n=15)(n=29)\end{array}$ & $\begin{array}{l}\text { Low risk wheezy - healthy } \\
\text { children }(n=29)(n=29)\end{array}$ & $\begin{array}{l}\text { High risk - low risk } \\
\text { wheezy children }\end{array}$ \\
\hline $\mathrm{FEV}_{0.5}$ z score & $\begin{array}{l}-1.4(-2.1 \text { to }-0.8) \\
p<0.001\end{array}$ & $\begin{array}{l}-0.8(-1.3 \text { to }-0.3) \\
p<0.01\end{array}$ & $\begin{aligned} & -0.7(-1.3 \text { to } 0.01) \\
p & =0.1\end{aligned}$ \\
\hline $\mathrm{FEF}_{25-75}$ z score & $\begin{array}{l}-1.2(-1.8 \text { to }-0.6) \\
p<0.001\end{array}$ & $\begin{array}{l}\quad-0.6(-1.0 \text { to }-0.2) \\
p<0.01\end{array}$ & $\begin{array}{l}-0.6(-1.2 \text { to }-0.1) \\
\mathrm{p}<0.05\end{array}$ \\
\hline $\mathrm{FEF}_{75}$ z score & $\begin{array}{l}-1.0(-1.5 \text { to }-0.3) \\
p<0.01\end{array}$ & $\begin{array}{l}\quad-0.4(-0.8 \text { to }-0.04) \\
p<0.05\end{array}$ & $\begin{aligned} & -0.5(-1.1 \text { to } 0.1) \\
p & =0.1\end{aligned}$ \\
\hline FVC z score & $\begin{array}{l}-1.2(-1.9 \text { to }-0.4) \\
p<0.01\end{array}$ & $\begin{aligned} & -0.5(-1.1 \text { to } 0.2) \\
p & =0.2\end{aligned}$ & $\begin{array}{l}-0.7(-1.4 \text { to }-0.04) \\
\mathrm{p}<0.05\end{array}$ \\
\hline $\mathrm{V}_{\text {maxFRC }}^{\prime}$ z score & $\begin{array}{l}\quad-0.7(-1.3 \text { to }-0.1) \\
p<0.05\end{array}$ & $\begin{aligned} & -0.2(-0.7 \text { to } 0.3) \\
p & =0.4\end{aligned}$ & $\begin{aligned} & -0.5(-1.1 \text { to } 0.1) \\
p & =0.1\end{aligned}$ \\
\hline Respiratory rate (bpm) & $\begin{aligned} & 0.2(-3.9 \text { to } 4.3) \\
p= & 0.9\end{aligned}$ & $\begin{aligned} & -0.5(-3.4 \text { to } 2.4) \\
p & =0.7\end{aligned}$ & $\begin{aligned} & 0.7(-3.4 \text { to } 4.8) \\
p= & 0.7\end{aligned}$ \\
\hline $\mathrm{Vt} / \mathrm{kg}(\mathrm{ml})$ & $\begin{aligned} & 0.1(-0.8 \text { to } 1.1) \\
p= & 0.8\end{aligned}$ & $\begin{aligned} & -0.1(-0.8 \text { to } 0.5) \\
p & =0.7\end{aligned}$ & $\begin{aligned} & 0.3(-0.5 \text { to } 1.0) \\
p= & 0.5\end{aligned}$ \\
\hline$t_{P T E F} / t_{E}$ & $\begin{aligned} & -0.04(-0.10 \text { to } 0.01) \\
p & =0.1\end{aligned}$ & $\begin{aligned} & -0.03(-0.08 \text { to } 0.02) \\
p & =0.2\end{aligned}$ & $\begin{aligned} & -0.01(-0.10 \text { to } 0.04) \\
p & =0.6\end{aligned}$ \\
\hline
\end{tabular}

Wheezy subgroups: "High risk" denotes wheezy children with a parental history of asthma or wheezing without colds and serum eosinophilia $>4 \%$; "Low risk" denotes wheezy children without such clinical history.

$\mathrm{FEV}_{0.5}$, forced expiratory volume at $0.5 \mathrm{~s}$; $\mathrm{FEF}_{75}$, forced expired flow after $75 \% \mathrm{FVC}$ has been exhaled; $\mathrm{FEF}_{25-75}$, average forced expired flow over the mid $50 \%$ of FVC; FVC, forced vital capacity; $\mathrm{t}_{\mathrm{PTEF}} / \mathrm{t}_{\mathrm{E}}$, ratio of time taken to reach peak tidal expiratory flow to total expiratory time; $\mathrm{V}_{\text {max }}^{\prime} \mathrm{RC}^{\prime}$ maximal forced flows at functional residual capacity; $\mathrm{Vt}$, tidal volume.

allergic disorders or parental asthma. Children born prematurely or small for gestational age were excluded from index and control groups. While these stringent criteria inevitably excluded a number of children who would otherwise have been eligible, they allowed us to undertake a comparison of steroid naïve, recurrently wheezy young children versus healthy controls, without additional bias related to preterm delivery ${ }^{13}$ or intrauterine growth restriction, ${ }^{14}$ both of which can impact negatively on subsequent lung development.

Among the wheezy children enrolled, $28 \%$ could not be tested: either because they became too old for inclusion or because of hospitalisation/treatment with corticosteroids/antileukotrienes before they could be tested. Results from this study may therefore underestimate the true magnitude of the difference between groups as some of the more severely affected children were excluded. Despite this, when using the raised volume technique, clear differences were evident not only between wheezy infants and healthy controls but within the wheezing group according to risk factors.

Index children were slightly older than controls at time of the test (table 1), both because of the requirement for at least three episodes of physician confirmed wheeze prior to recruitment and postponements of tests as a result of respiratory illness, particularly in those with viral associated wheeze. After adjustment for age and sex, the wheezy infants were significantly heavier, although not longer, than the healthy controls. While the reason for this is unclear, by expressing lung function as $z$ scores or adjusting for age and length when using MLR, such differences were accounted for when ascertaining the effect of wheeze on lung function. Turner et $a^{133}$ reported a negative association between postnatal weight gain and change in length adjusted $\mathrm{V}^{\prime}{ }_{\operatorname{maxFRC}}$ in some infants between 1 and 12 months of age. They speculated that, in infants with reduced birth weight but accelerated "catch-up" during infancy, somatic growth may outstrip that of the lungs, resulting in reduced lung function. Although we excluded any infants with low birth weight for gestational age, a similar phenomenon might have occurred in those with rapid weight gain. However, we did not observe any significant relationship between change in weight and lung function, once other covariants had been adjusted for.

Ideally we would have assessed bronchodilator responsiveness in this study but this would have prolonged test duration and potentially jeopardised success rates. Furthermore, although airway obstruction may be largely reversible in older subjects with asthma, bronchodilator response is far more variable among wheezy infants, many of whom may show no improvement or even paradoxical responses. ${ }^{22}$

\section{Power of study}

This study was well powered to identify clinically significant differences $(0.67 \mathrm{z}$ scores $)$ between wheezy children and controls. Original power calculations were based on 35 in each group. The final study population consisted of 73 children (44 wheezy, 29 controls). Retrospective power calculations confirmed that with a 1.5:1 imbalance between groups, there would be the same power as 35/group. Similarly, although there was an imbalance of 1.9:1 between the wheezy subgroups (29 low; 15 high risk), the total of 44 subjects provided the same power as 20/group. Nevertheless, the lower numbers meant that there was only $60 \%$ power of detecting differences as small as 0.67 $z$ scores ( $80 \%$ for detecting 0.9 z score), increasing the risk of type II errors during subgroup analysis, especially during MLR.

\section{Lung function testing and results}

The standardised approach to data collection and analysis between the two centres was one of the strengths of this study. The London team provided intensive training to the Lisbon principal investigator (LMB), followed by the establishment of identical infant lung function equipment and measurement protocols in Lisbon. In addition, regular inter-laboratory site visits and cross analysis of data were undertaken throughout the duration of the study to minimise bias.

Results from this study suggest that while lung function is reduced in infants with recurrent wheeze but low risk for subsequent asthma, these differences are less marked than in those at high risk. The reduction in FVC in the wheezy children, 
which was accompanied by reduced flows, was more evident in the high risk group, and probably reflects small airway obstruction and airway closure at low volumes during forced expiration rather than any alteration in lung growth or gas trapping during spontaneous breathing. While reductions in FVC can also occur because of gastric distension during the raised volume rapid thoraco-abdominal compression, ${ }^{28}$ we took particular care to exclude this possibility by checking that there was no systematic fall in FVC between the first and last manoeuvre. Similarly, data from manoeuvres where there was any indication of early termination of forced expiration were excluded (see online supplement).

We were not able to assess resting lung volume in this study because of the limited duration of sleep in many of the subjects but had there been any dynamic elevation of functional residual volume in those who wheezed, measures of $\mathrm{V}^{\prime}{ }_{\max }$ RRC would have been obtained at a higher volume than in healthy controls, thereby minimising differences between groups. ${ }^{21}$ This, together with the intrinsic variability of end expiratory level during infancy, could contribute to the reduced sensitivity of the partial compared with the raised volume technique in differentiating between those with and without prior wheeze. Although some studies have reported reductions in $\mathrm{V}^{\prime}$ maxFRC in wheezy infants, ${ }^{345}$ recent publications suggest that the raised volume technique is more discriminative. ${ }^{21-24}$

It has been reported that tidal breathing indices such as $t_{\text {PTEF: }} t_{E}$ may be associated with subsequent wheezing or asthma in later life. ${ }^{20}{ }^{36}$ Significant associations between $t_{\text {PTEF }}: t_{E}$ and subsequent outcome have, however, largely been limited to large epidemiological studies with premorbid assessments of tidal breathing measured shortly after birth, a time when modulation of expiratory flows and timing is most active. In this study, $t_{\mathrm{PTEF}}: \mathrm{t}_{\mathrm{E}}$ was slightly, but not significantly, lower in wheezy infants; this relative lack of discrimination of tidal breathing parameters in older infants with prior wheeze being in keeping with previous reports. ${ }^{37}$

In contrast with previous publications, ${ }^{27}$ we did not find a significant effect of maternal smoking during pregnancy although flows tended to be lower in those exposed. This may reflect the relatively small subgroups, the highly selected nature of the population or some interaction between the effects of wheezing and maternal smoking on measured flows. In support of this contention, when analysis was limited to wheezy infants, flows were significantly lower in those whose mothers had smoked.

\section{CONCLUSIONS}

We have demonstrated that lung function is reduced in infants and young children with recurrent wheeze, and that these changes are most marked in those at high risk of subsequent asthma. Findings from this study suggest that the raised volume technique is able to identify diminished lung function in wheezy infants compared with controls, and between wheezy subgroups according to clinical risk factors. Given the overlap between groups, it is, however, unlikely that such tests would be able to predict persistent wheeze within individuals.

While further work is still required to establish short and long term repeatability, use of such physiological measures in combination with clinical symptoms and risk factors could potentially influence therapeutic interventions.

Acknowledgements: We thank the parents who consented for their infants and young children to participate in this study and staff at the Hospital de Dona Estefânia, Lisbon, and Portex Respiratory Unit, UCL Institute of Child Health, London, for their support. We thank Dr Sooky Lum for her assistance in providing technical training.
Funding: We thank Schering Plough for financial support towards travel expenses which enabled collaborative work between the two institutions (Hospital de Dona Estefânia, Lisbon and Portex Respiratory Unit, UCL Institute of Child Health, London).

Competing interests: None.

Ethics approval: The ethics committees at the Lisbon and London institutions approved the study.

\section{REFERENCES}

1. Clough JB, Keeping KA, Edwards LC, et al. Can we predict which wheezy infants will continue to wheeze? Am J Respir Crit Care Med 1999;160:1473-80.

2. Martinez FD, Wright AL, Taussig LM, et al. Asthma and wheezing in the first six years of life. The Group Health Medical Associates. N Engl J Med 1995;332:133-8.

3. Taussig LM, Wright AL, Holberg CJ, et al. Tucson Children's Respiratory Study: 1980 to present. J Allergy Clin Immunol 2003;111:661-75.

4. De Sario M, Di Domenicantonio R, Corbo G, et al. Characteristics of early transient, persistent, and late onset wheezers at 9 to 11 years of age. J Asthma 2006;43:633-8.

5. Stern DA, Morgan WJ, Wright AL, et al. Poor airway function in early infancy and lung function by age 22 years: a non-selective longitudinal cohort study. Lancet 2007;370:758-64.

6. Phelan PD, Robertson CF, Olinsky A. The Melbourne Asthma Study: 1964-1999. J Allergy Clin Immunol 2002;109:189-94.

7. Sears MR, Greene JM, Willan AR, et al. A longitudinal, population-based, cohort study of childhood asthma followed to adulthood. N Engl J Med 2003;349:1414-22.

8. Castro-Rodriguez JA, Holberg CJ, Wright AL, et al. A clinical index to define risk of asthma in young children with recurrent wheezing. Am J Respir Crit Care Med 2000;162:1403-6.

9. Morais-Almeida M, Gaspar A, Pires G, et al. Risk factors for asthma symptoms at school age: an 8-year prospective study. Allergy Asthma Proc 2007;28:183-9.

10. Young S, Arnott J, O'Keeffe PT, et al. The association between early life lung function and wheezing during the first 2 yrs of life. Eur Respir J 2000;15:151-7.

11. Murray CS, Pipis SD, McArdle EC, et al. Lung function at one month of age as a risk factor for infant respiratory symptoms in a high risk population. Thorax 2002;57:388-92

12. Dezateux C, Stocks J, Dundas I, et al. Impaired airway function and wheezing in infancy: the influence of maternal smoking and a genetic predisposition to asthma. Am J Respir Crit Care Med 1999;159:403-10.

13. Hoo AF, Dezateux C, Henschen M, et al. Development of airway function in infancy after preterm delivery. J Pediatr 2002;141:652-8.

14. Hoo AF, Stocks J, Lum S, et al. Development of lung function in early life: influence of birth weight in infants of nonsmokers. Am J Respir Crit Care Med 2004;170:527-33.

15. Oswald H, Phelan PD, Lanigan A, et al. Childhood asthma and lung function in mid adult life. Pediatr Pulmonol 1997;23:14-20.

16. Turner SW, Palmer LJ, Rye PJ, et al. The relationship between infant airway function, childhood airway responsiveness, and asthma. Am J Respir Crit Care Med 2004;169:921-7.

17. Hibbert ME, Lannigan A, Landau LI, et al. Lung function values from a longitudinal study of healthy children and adolescents. Pediatr Pulmonol 1989;7:101-9.

18. Wilson NM, Lamprill JR, Mak JC, et al. Symptoms, lung function, and beta2adrenoceptor polymorphisms in a birth cohort followed for 10 years. Pediatr Pulmonol 2004;38:75-81.

19. Delacourt C, Benoist MR, Waernessyckle S, et al. Relationship between bronchial responsiveness and clinical evolution in infants who wheeze: a four-year prospective study. Am J Respir Crit Care Med 2001;164:1382-6.

20. Haland G, Carlsen KC, Sandvik L, et al. Reduced lung function at birth and the risk of asthma at 10 years of age. N Engl J Med 2006;355:1682-9.

21. Ranganathan SC, Bush A, Dezateux C, et al. Relative ability of full and partial forced expiratory maneuvers to identify diminished airway function in infants with cystic fibrosis. Am J Respir Crit Care Med 2002;166:1350-7.

22. Modl M, Eber E, Weinhandl E, et al. Assessment of bronchodilator responsiveness in infants with bronchiolitis. A comparison of the tidal and the raised volume rapid thoracoabdominal compression technique. Am J Respir Crit Care Med 2000;161:763-8.

23. Turner DJ, Lanteri CJ, Le Souëf PN, et al. Improved detection of abnormal respiratory function using forced expiration from raised lung volume in infants with cystic fibrosis. Eur Respir J 1994;7:1995-9.

24. Wildhaber JH, Dore ND, Devadason SG, et al. Comparison of subjective and objective measures in recurrently wheezy infants. Respiration 2002;69:397-405.

25. Saito J, Harris WT, Gelfond J, et al. Physiologic, bronchoscopic, and bronchoalveolar lavage fluid findings in young children with recurrent wheeze and cough. Pediatr Pulmonol 2006;41:709-19.

26. Goldstein AB, Castile RG, Davis SD, et al. Bronchodilator responsiveness in normal infants and young children. Am J Respir Crit Care Med 2001;164:447-54.

27. Freeman JV, Cole TJ, Chinn S, et al. Cross sectional stature and weight reference curves for the UK, 1990. Arch Dis Child 1995;73:17-24.

28. ATS_ERS Consensus Statement, Lum S, Stocks J, et al. Raised volume forced expirations in infants: Recommendations for current practice. Am J Respir Crit Care Med 2005;172:1463-71.

29. Sly $\mathbf{P}$, Tepper R, Henschen $\mathbf{M}$, et al. Standards for infant respiratory function testing Tidal forced expirations. Eur Respir J 2000;16:741-8. 
30. Hoo AF, Dezateux C, Hanrahan J, et al. Sex-specific prediction equations for V' ${ }_{\text {maxFRC }}$ in infancy: a multi-center collaborative study. Am J Respir Crit Care Med 2002;165:1084-92.

31. Jones $\mathbf{M}$, Castile $\mathrm{R}$, Davis $\mathbf{S}$, et al. Forced expiratory flows and volumes in infants: normative data and lung growth. Am J Respir Crit Care Med 2000;161:353-9

32. Whitley E, Ball J. Statistics Review 4: Sample size calculations. UK: Biomed Central Ltd, 2002. http://ccforum.com/content/6/4/335 (accessed 19 January 2009).

33. Turner S, Zhang G, Young S, et al. Associations between postnatal weight gain, change in postnatal pulmonary function, formula feeding and early asthma. Thorax 2008;63:234-9.
34. Clarke JR, Reese A, Silverman M. Bronchial responsiveness and lung function in infants with lower respiratory tract illness over the first six months of life. Arch Dis Child 1992;67:1454-8.

35. Stick SM, Arnott J, Turner DJ, et al. Bronchial responsiveness and lung function in recurrently wheezy infants. Am Rev Respir Dis 1991;144:1012-15.

36. Young S, Arnott J, Le Souef PN, et al. Flow limitation during tidal expiration in symptom-free infants and the subsequent development of asthma. J Pediatr 1994;124:681-8.

37. Dezateux C, Stocks J, Wade AM, et al. Airway function at one year: association with premorbid airway function, wheezing and maternal smoking. Thorax 2001;56:680-6.

\section{BMJ Careers online re-launches}

BMJ Careers online has re-launched to give you an even better online experience. You'll still find our online services such as jobs, courses and careers advice, but now they're even easier to navigate and quicker to find.

New features include:

- Job alerts - you tell us how often you want to hear from us with either daily or weekly alerts

- Refined keyword searching making it easier to find exactly what you want

- Contextual display - when you search for articles or courses we'll automatically display job adverts relevant to your search

- Recruiter logos linked directly to their organisation homepage - find out more about the company before you apply

- RSS feeds now even easier to set up

Visit careers.bmj.com to find out more. 